I have a few copies of my paper, and will send one to anybody who has not access to the Journal of the Institution of Electrical Engineers, and who is specially interested in the subject.

Athenæum Club, Pall Mall, London.

\section{International Latin.}

I HAVE always shared the regret of your correspondents that Latin has now ceased to be employed as the international language of science, although for more than a thousand years after it had ceased to be a vernacular it had, among men of education, maintained its position as a living language, adapting itself to the varying needs of the times. I have devoted some attention to the development during the Middle Ages and succeeding centuries of the branches of science in which I am more especially interested, and have been struck by the clear, fluent Latin in which the majority of the scientific treatises were written. That of Agricola, Encelius (Entzelt), Gesner, Camden, and Cæsalpinus in the sixteenth century; Francisco Imperato and Aldrovandi in the seventeenth; and Isaac Lawson, Cramer, and Linnæus in the eighteenth, and most of their fellow-workers is, as a rule, as easy to follow as French, in spite of the handicap of the want of articles, the most serious defect of Latin.

It was the Latinists themselves who were primarily responsible for the modern disuse of the language. They insisted that the diction of Cicero, rather than that of Pliny, should be followed, and as they spoke with authority, there was no one hardy enough to contradict them, so that the unfortunate man of science had to face a hail of ridicule if he failed to reproduce the mannerisms which were held up for his imitation, while if he succeeded his pages were almost unreadable for most of those who would have been interested in their contents.

If Latin were ever again to come into use for scientific purposes, it would only be by assimilating its style and idioms to those of its daughter languages at the present time, by accommodating itself to the changes of meaning which have overtaken so many of its words, and by borrowing freely from their vocabulary, especially in the case of terms which are practically international. At the same time the inflexions and syntax of classical Latin would be generally, but not slavishly, followed.

I am afraid, however, that it is too late to undo the work of those who have slain the object of their affections by strenuous efforts to renew the golden age of its early youth when by far the more important portion of its long career of usefulness still lay before it; and now that it is, as it would seem, really dead, had we not better regretfully but resolutely bury it out of sight and turn our thoughts to the flexible idiom handed down to us by our forefathers, which is already understood throughout the whole civilised world?

Imperial College of Science and Technology South Kensington, March 28.

\section{Osmotic Pressure or Osmotic Suction-Which?}

THE interesting controversy between Profs. van Laar and Ehrenfest, referred to in NATURE of March 16 , again raises the question of the cause for the approximate equality between osmotic pressure and gas pressure. In this connection the following simple proof, based on the kinetic theory, of van't Hoff's well-known relationship, may be of interest.

The tendency of a liquid to diffuse is measured by its diffusion pressure, which may be defined the bombardment pressure exerted by the liquid molecules on either side of a plane of unit No. 2423 , voL. 97$]$ area placed anywhere within the liquid. If we regard a perfect liquid as formed by the compression of a perfect gas until the molecules almost touch one another, it will be seen that the diffusion pressure is proportional to the number of molecules in unit volume, or the absolute concentration, and also to the absolute temperature. The diffusion pressure for ordinary liquids has a very large value. For instance, if water were a perfect liquid, its diffusion pressure would be about 1200 atmospheres.

Since the absolute concentration of a solvent is reduced by the introduction of a solute, it is evident that diffusion pressure is reduced in the same way; so that the diffusion pressure of the solvent in a solution is always less than that in the pure solvent itself. Hence solvent travels across a membrane from the pure solvent side to the solution side, unless a hydrostatic pressure equal to the difference between the two diffusion pressures is placed on the solution. The osmotic pressure, which is defined as the aforesaid hydrostatic pressure, is therefore proportional to the difference between the absolute concentrations of the solvent on the two sides of the membrane. Further, it is also approximately proportional to the concentration of the solute because the latter is itself approximately equal to the difference in solvent concentration on the two sides, since the process of solution consists essentially in the spatial replacement of part of the solvent molecules by a more or less equal number of solute molecules.

Next as regards the gas relationship. Consider the case of a pure solvent separated from its solution by means of a semipermeable membrane (diagram I.). Remove from the solution side all the solvent molecules; and also an equal number from the pure solvent side. The sys-

tem then assumes the ap-

pearance shown in diagram II. Now this process merely reduces the absolute c o ncentrations and diffusion pressures on the two sides of the membrane to an equal extent; but leaves una ltered the differences. The

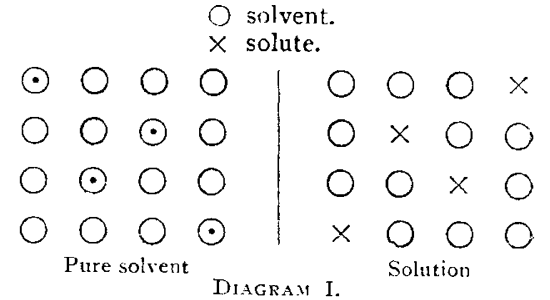

$\odot$

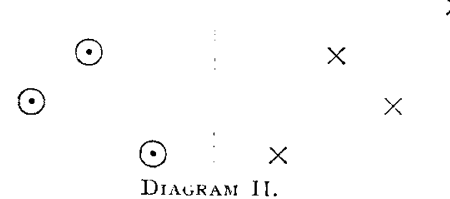
residue of sol

vent molecules $[\odot]$ will diffuse across the membrane just as before; whilst the solute molecules will bombard the membrane. Moreover, the pressure of the solvent residue on the one side will be equal to the pressure of the solute on the other; and both will be equal to the corresponding gas pressure, since the molecules are at distances from one another comparable to gas distances. Hence to prevent the residue of solvent from flowing across the membrane, a hydro. static pressure equal to the gas pressure will have to be applied. The usual way of doing this is to make the solution into a kind of piston.

On the other hand, the solute bombards the membrane with a pressure equal to the corresponding gas pressure, whether a hydrostatic pressure is placed on the solution or not. The solvent itself can exert no pressure on the membrane, since it is supposed to be able to travel across the membrane just as if the latter were non-existent. 